\title{
Early discontinuation of endocrine therapy for breast cancer: who is at risk in clinical practice?
}

\author{
Anna Kemp ${ }^{1 *}$, David B Preen ${ }^{1}$, Christobel Saunders ${ }^{2}$, Frances Boyle $^{3}$, Max Bulsara $^{4}$, Eva Malacova ${ }^{1}$ \\ and Elizabeth E Roughead ${ }^{5}$
}

\begin{abstract}
Purpose: Despite evidence supporting at least five years of endocrine therapy for early breast cancer, many women discontinue therapy early. We investigated the impact of initial therapy type and specific comorbidities on discontinuation of endocrine therapy in clinical practice.

Methods: We identified women in a population-based cohort with a diagnosis of early breast cancer and an incident dispensing of anastrozole, letrozole or tamoxifen from 2003-2008 ( $N=1531)$. Pharmacy and health service data were used to determine therapy duration, treatment for pre-existing and post-initiation comorbidities (anxiety, depression, hot flashes, musculoskeletal pain, osteoporosis, vaginal atrophy), demographic and other clinical characteristics. Time to discontinuation of initial, and any, endocrine therapy was calculated. Cox regression determined the association of different characteristics on early discontinuation.

Results: Initial endocrine therapy continued for a median of 2.2 years and any endocrine therapy for 4.8 years. Cumulative probability of discontinuing any therapy was $17 \%$ after one year and $58 \%$ by five years. Initial tamoxifen, pre-existing musculoskeletal pain and newly-treated anxiety predicted shorter initial therapy but not discontinuation of any therapy. Early discontinuation of any therapy was associated with newly-treated hot flashes ( $H R=2.1$, $95 \% \mathrm{Cl}=1.3-3.3)$, not undergoing chemotherapy $(\mathrm{HR}=1.4,95 \% \mathrm{Cl}=1.1-1.8)$ and not undergoing mastectomy $(\mathrm{HR}=1.5,95 \% \mathrm{Cl}=1.2-1.8)$.

Conclusions: Less than half of women completed five years of endocrine therapy. Women at greatest risk of stopping any therapy early were those with newly-treated hot flashes, no initial chemotherapy, or no initial mastectomy. This suboptimal use means that the reductions in recurrence demonstrated in clinical trials may not be realised in practice.
\end{abstract}

Keywords: Persistence; Adherence; Tamoxifen; Aromatase inhibitors; 45 and up study

\section{Background}

Endocrine therapy is the foundation of post-surgical treatment for women with hormone-dependent early breast cancer (Cheung 2007). Clinical trials clearly demonstrate that endocrine therapy halves the risk of recurrence and reduces cancer-related mortality when used for at least five years (ATAC Trialists' Group 2005; Bliss et al. 2012; Coates et al. 2007; Davies and Adjuvant Tamoxifen: Longer Against Shorter (ATLAS) Collaborative Group 2013; Forbes et al. 2008; Gray and aTTom Collaborative

\footnotetext{
* Correspondence: anna.kemp@uwa.edu.au

${ }^{1}$ Centre for Health Services Research, School of Population Health, The

University of Western Australia, 35 Stirling Hwy, Crawley, WA 6009, Australia

Full list of author information is available at the end of the article
}

Group 2013). Women using endocrine therapy for shorter time periods are at increased risk of recurrence and have higher mortality (Hsieh et al. 2014; McCowan et al. 2008; Swedish Breast Cancer Cooperative Group 1996; Yood et al. 2008). Despite strong empirical support for at least five years of endocrine therapy, early discontinuation of therapy in clinical practice has been reported in many European and North American studies (Hershman et al. 2010; Huiart et al. 2011; McCowan et al. 2008; Owusu et al. 2008; Partridge et al. 2008; van Herk-Sukel et al. 2010). A review of endocrine therapy duration of use outside of clinical trials reported that between 13\%

\section{实


and $20 \%$ of women had discontinued therapy within one year, and $31 \%-73 \%$ had discontinued within five years (Murphy et al. 2012).

A number of demographic and clinical factors have been associated with early discontinuation including younger and older age ( $<45$ years or $>70$ years) (Barron et al. 2007; Hershman et al. 2010; Nekhlyudov et al. 2011; van HerkSukel et al. 2010), being married (Kimmick et al. 2009), social disadvantage (Nekhlyudov et al. 2011), having a node-negative tumour (Kimmick et al. 2009), not undergoing chemotherapy or mastectomy (Barron et al. 2007; Hershman et al. 2010), and number of comorbidities (Demissie et al. 2001; Hershman et al. 2010; Kimmick et al. 2009; Neugut et al. 2011; van Herk-Sukel et al. 2010). Number of comorbidities has typically been ascertained using the Charlson comorbidity index (Charlson et al. 1987 ) or number of prescriptions used prior to commencing therapy, and reported associations with persistence to endocrine therapy have been mixed. Endocrine therapy may cause or exacerbate specific conditions including anxiety (Grunfeld et al. 2005; Güth et al. 2011), depression (Grunfeld et al. 2005), hot flashes (Grunfeld et al. 2005; Güth et al. 2011), musculoskeletal pain (Chim et al. 2013; Güth et al. 2011;), osteoporosis (Bell et al. 2013), and vaginal atrophy (Fallowfield et al. 2004). Self-report suggests that these comorbidities are the reason some women discontinue therapy (Murphy et al. 2012) but the role of specific comorbidities has not been examined in observational studies of discontinuation.

A number of observational studies of endocrine therapy duration have ended follow-up when a woman's initial therapy is discontinued, reflecting the prominence of tamoxifen therapy until the mid-2000's (Barron et al. 2007; McCowan et al. 2008; Partridge et al. 2003; van Herk-Sukel et al. 2010). There are few data to indicate whether characteristics associated with discontinuation of initial therapy (including initial therapy type) are associated with discontinuation of any endocrine therapy outside of clinical trials. One study of 4917 women with early breast cancer compared characteristics predicting discontinuation of initial therapy and any therapy (van Herk-Sukel et al. 2010). The authors reported that having $\geq 2$ comorbidities was associated with shorter duration of any endocrine therapy but found no association with discontinuation of initial therapy (van Herk-Sukel et al. 2010). Another study compared duration of initial therapy in women commencing with tamoxifen or an aromatase inhibitor (AI: anastrozole, letrozole or exemestane) and reported greater discontinuation for tamoxifen users than those taking AIs at five years (31\% vs. 19\%) (Huiart et al. 2011).

The aim of this study was to determine duration of use for initial endocrine therapy, and any endocrine therapy by women treated for early breast cancer in clinical practice; and the impact of initial therapy type and specific comorbidities on early discontinuation.

\section{Methods}

\section{Study population}

Participants were drawn from the 45 and Up Study cohort, a population-based cohort of approximately 267,000 adults (143,014 women) aged $\geq 45$ years residing in New South Wales (NSW), Australia (45 and Up Study Collaborators 2008). All cohort members provided written consent to join the 45 and Up Study, have their routinelycollected health data linked, and for these data to be provided to third-party researchers for approved projects.

\section{Data sources and linkage}

We accessed unit-record, linked data from: i) the 45 and Up Study baseline survey, ii) NSW Central Cancer Registry, iii) NSW Admitted Patient Data Collection (all admissions to public and private hospitals), iv) Pharmaceutical Benefits Scheme (PBS) claims (all subsidised medicines), v) Medicare Benefits Schedule (MBS) claims (all subsidised outpatient consultations and investigations), and vi) NSW Registry of Births, Deaths, and Marriages. PBS and MBS data were supplied by the Department of Human Services, and remaining datasets were linked by the NSW Centre for Health Record Linkage (Centre for Health Record Linkage (CHeReL) 2009). The study period was defined as 1 January 2003 to 30 November 2011.

\section{Selection of cohort}

The cohort comprised women in the 45 and Up Study with an incident dispensing of anastrozole, letrozole or tamoxifen between July 2003 and December 2008 and a diagnosis of invasive breast cancer listed on the Cancer Registry. A six month washout period from January-June 2003 was used to remove the 'prevalent pool' of women dispensed endocrine therapy. Women were excluded from the analysis if they had either a distant tumour at diagnosis, an initial dispensing date prior to diagnosis, or a period $>18$ months between diagnosis and commencing endocrine therapy. The final study sample comprised 1531 women.

\section{Determining duration of endocrine therapy use}

The supply period for all medicines was considered to be pack size plus five days to allow for refill (i.e. 35 days) with the exception of tamoxifen $20 \mathrm{mg}$ which was 65 days. Discontinuation was considered to have occurred if there was no dispensing of any endocrine therapy (anastrozole, exemestane, letrozole or tamoxifen) for a period of >180 days (Hershman et al. 2010; Nekhlyudov et al. 2011). Duration of endocrine therapy use was defined in two ways: i) time to last recorded dispensing of the 
participants' initial endocrine therapy plus the supply period and ii) time to last recorded dispensing of any endocrine therapy plus the supply period.

\section{Ascertaining comorbidities, recurrence and death} Comorbid anxiety, depression, hot flashes, musculoskeletal pain, osteoporosis and vaginal atrophy were ascertained by claims for $\geq 1$ specified PBS items dispensed during the study period (Table 1). PBS data do not capture information on indication, however, many items are restricted to use for particular indications. For example, PBS-supply of venlafaxine is restricted to use for major depressive disorders (Australian Government Department of Health 2013a). Comorbidities were considered to be 'pre-existing' if the relevant medication was dispensed before the incident endocrine therapy and 'newly-treated' if dispensed for the first time after endocrine therapy commenced. Breast cancer recurrence is not routinely collected in the Cancer Registry so was ascertained from: i) specified surgeries, chemotherapy or radiotherapy occurring for the first time $>18$ months from the date of diagnosis, or $>12$ months after previous claims for these events, or ii) first dispensing of a medicine indicated only for advanced breast cancer (Table 1). Fact and date of death were obtained from the death register for the years 2003-2010. Deaths occurring in 2011 were ascertained from PBS data by having no dispensing for any medicines for a period of $>180$ days. Deaths ascertained using this algorithm were validated against the death register for the period 2003-2010, with a resulting sensitivity and specificity of $98.2 \%$ and $90.2 \%$, respectively. The algorithm detected $98 \%$ of deaths to within 1 calendar month of the date of death listed in the death register.

\section{Other covariates}

Tumour stage and size were obtained from the Cancer Registry. Women undergoing mastectomy or chemotherapy prior to commencing endocrine therapy were identified through specified hospital and MBS items (Table 1). Specialty of the treating clinician was obtained from participant's MBS claims between diagnosis and start of endocrine therapy (i.e. medical oncologist/other). Residential location was assessed using the Accessibility/ Remoteness Index of Australia Plus (ARIA+) (Australian

Table 1 Medicine and service codes used to identify endocrine therapies, comorbidity and cancer recurrence, by data source

\begin{tabular}{ll}
\hline Description $\quad$ Name and item code \\
\hline Pharmaceutical benefits scheme
\end{tabular}

Endocrine therapies subsidised for early breast cancer

Anxiety treatments

Depression treatments

Hot flash treatments

Musculoskeletal pain treatments

Osteoporosis treatments

Vaginal atrophy treatment

Medicines for advanced breast cancer ${ }^{b}$

Medicare benefits schedule

Chemotherapy

Radiotherapy

Admitted patient data collection

Services for cancer recurrence
Anastrozole (8179L); exemestane (8506Q); letrozole (8245Y); tamoxifen (2109B, 2110C).

Alprazolam (2130D, 2131E, 2132F, 8118G); diazepam (3161J, 3162K); oxazepam 3132W 3133X).

Amitriptyline (2417F, 2418G, 2429W); citalopram (8220P, 8702B, 8703C); dothiepin (1357K, 1358L); doxepin (1011F, 1012G, 1013H); escitalopram (8700X, 8701Y, 9433L, 9711D, 9727Y, 9728B); fluoxetine (1434L, 8270G); fluvoxamine (8174F); imipramine (2421K); mianserin (1627P, 1628Q); moclobemide (1900B, 8003F); mirtazapine (8513C, 8855C, 8856D, 8857E, 8883M); nortriptyline (2522R, 2323T); paroxetine (2242B); reboxetine (8583R); sertraline (2236Q, 2237R, 8836C, 8837D); venlafaxine ${ }^{a}$ (8068P, 8301X, 8302Y, 8868R).

Clonidine $(3141 \mathrm{H}, 3145 \mathrm{M})$.

Celecoxib (8439E, 8440F), diclofenac (1299J, 1300K, 1332D), ibuprofen (3190X, 3192B, 3198H, 5121M, $5124 Q)$, indomethacin (2454E, 2757D); ketoprofen (1588N, 1590Q); meloxicam (8561N, 8562P, 8887R, 8888T); naproxen (1614Y, 1615B, 1659H, 1674D, 1795L); piroxicam (1895R, 1896T, 1897W, 1898X); rofecoxib (8471W, 8472X); sulindac (2047R, 2048T); tiaprofenic acid (2103Q).

Alendronate (8102K, 8511Y, 9012 H, 9183H, 9351E); etidronate (8056B); risedronate (8481J, 8621R, 8899J, 9147K, 9391G); strontium (3036T); zoledronate (9288W).

Oestriol (1771F, 1776L, 1781R).

Capecitabine (8362D, 8631C); lapatinib (9148L); medroxyprogesterone (2728N); megestrol (2734X), toremifene (8216K); vinorelbine (8280T, 8281W, 9009E, 9010F).

13915, 13918, 13921, 13924, 13927, 13930 13933, 13936

15000-15012, 15100-15115, 15211-15217, 15219-15232, 15234-15247, 15249-15262, 15264-15272, 15303-15337, 15339-15357, 15339-15357.
Chemotherapy (13915, 13918, 13921, 13924, 13927, 13930 13933, 13936); lumpectomy (31500, 31503, 31506, 31509, 31512); mastectomy (31518, 31524); oophorectomy (35638, 35673, 35712, 35716, 35717, 35753, 35754).

${ }^{a}$ Venlafaxine subsidy is restricted to use for major depressive disorders but some off-label or dual use may occur for hot flashes.

${ }^{\mathrm{b}}$ These therapies are not subsidised for the treatment of early breast cancer. 
Population and Migration Research Centre 2013). Annual household income, highest level of education, marital status and country of birth were reported by participants at recruitment to the 45 and Up Study. County of birth was categorised as 'Australia,' 'New Zealand (NZ) or the United Kingdom (UK)', or 'other countries'.

\section{Statistical analysis}

Kaplan-Meier curves were used to determine time from first endocrine therapy dispensing until discontinuation of initial therapy, and discontinuation of any therapy. Follow-up was censored at five years after initial endocrine dispensing, recurrence, death, or study end; whichever occurred first. Univariate and multivariate Cox-proportional hazards models were used to determine the association between a range of clinical and demographic characteristics with discontinuation of endocrine therapy before five years (early discontinuation). All variables were included in the multivariate (adjusted) models. Hazard ratios (HR) and $95 \%$ confidence intervals (CI) were calculated for each characteristic. All analyses were conducted using IBM SPSS version 19.

\section{Results}

\section{Time to discontinuation of endocrine therapy}

The median time for participants to discontinue their initial endocrine therapy was 2.2 years (range 0.8-4.9, Figure 1). Use of initial therapy had ceased for $32 \%$ of women at one year, increasing to $81 \%$ by five years. The median time for discontinuation of any endocrine therapy was considerably longer at 4.8 years. Cumulative probability of discontinuing any endocrine therapy was $17 \%$ after one year, $27 \%$ at two years, $31 \%$ at three years, and $58 \%$ by five years.

\section{Characteristics associated with discontinuation of initial therapy}

Time to discontinuation of initial therapy varied by therapy type in both the unadjusted and adjusted models (Table 2). A history of anxiety, depression, hot flashes, osteoporosis or vaginal atrophy before commencing endocrine therapy did not impact on treatment duration. However, women with pre-existing musculoskeletal pain were significantly more likely to discontinue their initial therapy compared with other women (adjusted $\mathrm{HR}=1.3$, 95\% CI $=1.1-1.5)$. Women newly-treated for anxiety, depression, flashes or vaginal atrophy after commencing endocrine therapy discontinued therapy earlier than women without these comorbidities but only newlytreated anxiety remained significant in the adjusted model ( $\mathrm{HR}=1.5,95 \% \mathrm{CI}=1.1-1.9)$. Age, year of diagnosis, stage at diagnosis, no chemotherapy, no mastectomy and not seeing a medical oncologist were not related to duration of initial therapy in the adjusted model. Similarly, discontinuation of initial therapy was not associated with any demographic factors in the adjusted model including geographic remoteness, income, education, marital status or birth country.

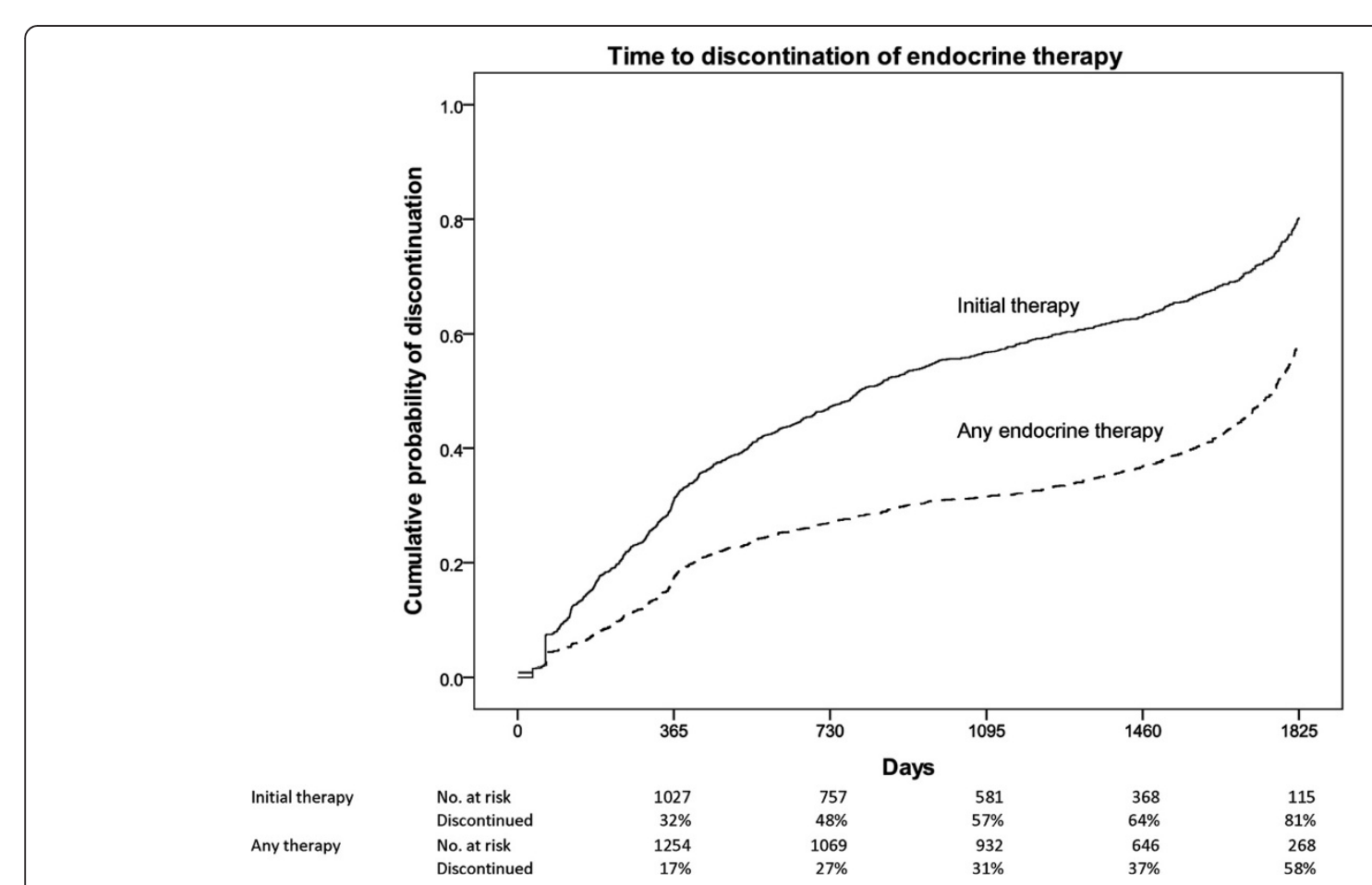

Figure 1 Kaplan-Meier graph showing time to discontinuation of initial endocrine therapy, and any endocrine therapy. 
Table 2 Results of unadjusted and adjusted Cox proportional hazards models for discontinuation of initial or any endocrine therapy, by specified clinical and demographic characteristics

\begin{tabular}{|c|c|c|c|c|c|}
\hline \multirow{2}{*}{$\begin{array}{l}\text { Clinical and demographic } \\
\text { characteristics }\end{array}$} & \multirow[t]{2}{*}{ N (\%) } & \multicolumn{2}{|c|}{ Initial endocrine therapy } & \multicolumn{2}{|c|}{ Any endocrine therapy } \\
\hline & & $\begin{array}{c}\text { Unadjusted hazard ratio } \\
(95 \% \mathrm{Cl})\end{array}$ & $\begin{array}{c}\text { Adjusted hazard ratio } \\
(95 \% \mathrm{Cl})\end{array}$ & $\begin{array}{c}\text { Unadjusted hazard ratio } \\
(95 \% \mathrm{Cl})\end{array}$ & $\begin{array}{c}\text { Adjusted hazard ratio } \\
(95 \% \mathrm{Cl})\end{array}$ \\
\hline \multicolumn{6}{|l|}{ Initial therapy: } \\
\hline Tamoxifen & 917 (59.9\%) & 1.00 & 1.00 & 1.00 & 1.00 \\
\hline Anastrozole & $518(33.8 \%)$ & $0.53(0.46-0.61)$ & $0.57(0.48-0.67)$ & $0.64(0.54-0.76)$ & $0.90(0.74-1.09)$ \\
\hline Letrozole & $96(6.3 \%)$ & $0.60(0.45-0.80)$ & $0.65(0.49-0.87)$ & $0.75(0.53-1.07)$ & $1.04(0.72-1.50)$ \\
\hline \multicolumn{6}{|l|}{ Year of diagnosis: } \\
\hline$\geq 2004$ & $1297(84.7 \%)$ & 1.00 & 1.00 & 1.00 & 1.00 \\
\hline$<2004$ & $234(15.3 \%)$ & $1.77(1.52-2.06)$ & $0.89(0.63-1.25)$ & $2.26(2.16-3.04)$ & $1.56(1.01-2.40)$ \\
\hline \multicolumn{6}{|l|}{ Age: } \\
\hline$<55$ years & $454(29.7 \%)$ & 1.00 & 1.00 & 1.00 & 1.00 \\
\hline $55-74$ years & $878(57.3 \%)$ & $0.93(0.82-1.07)$ & $1.03(0.88-1.20)$ & $1.08(0.91-1.28)$ & $1.07(0.88-1.29)$ \\
\hline$\geq 75$ years & $199(13.0 \%)$ & $0.76(0.62-0.94)$ & $0.79(0.62-1.01)$ & $1.22(0.96-1.55)$ & $1.31(0.98-1.75)$ \\
\hline \multicolumn{6}{|l|}{ Tumour size: } \\
\hline$>2 \mathrm{~cm}$ & $533(34.8 \%)$ & 1.00 & 1.00 & 1.00 & 1.00 \\
\hline$<1-2 \mathrm{~cm}$ & $528(34.5 \%)$ & $1.02(0.88-1.19)$ & $0.94(0.80-1.11)$ & $1.09(0.90-1.32)$ & $0.90(0.73-1.11)$ \\
\hline$\leq 1 \mathrm{~cm}$ & $176(11.5 \%)$ & $1.01(0.82-1.25)$ & $0.84(0.67-1.06)$ & $1.47(1.15-1.90)$ & $1.13(0.86-1.48)$ \\
\hline Missing & $294(19.2 \%)$ & $1.75(1.49-2.06)$ & $1.43(1.03-2.00)$ & $2.52(2.07-3.07)$ & $1.25(0.82-1.91)$ \\
\hline \multicolumn{6}{|l|}{ Stage: } \\
\hline Node-positive & 608 (39.7\%) & 1.00 & 1.00 & 1.00 & 1.00 \\
\hline Node-negative & $865(56.5 \%)$ & $1.07(0.94-1.21)$ & $0.96(0.84-1.10)$ & $1.37(1.16-1.60)$ & $1.15(0.97-1.36)$ \\
\hline Missing & $58(3.8 \%)$ & $1.16(0.85-1.60)$ & $0.89(0.63-1.26)$ & $1.28(0.85-1.94)$ & $0.73(0.47-1.14)$ \\
\hline No chemotherapy & $1145(74.7 \%)$ & $1.26(1.09-1.46)$ & $1.05(0.87-1.26)$ & $2.12(1.72-2.62)$ & $1.42(1.11-1.83)$ \\
\hline No mastectomy & $1103(72.0 \%)$ & $1.21(1.06-1.39)$ & $1.06(0.91-1.23)$ & $1.77(1.47-2.13)$ & $1.45(1.18-1.77)$ \\
\hline No medical oncologist ${ }^{a}$ & $922(60.2 \%)$ & $1.16(1.02-1.32)$ & $1.05(0.90-1.23)$ & $1.84(1.55-2.17)$ & $1.20(0.98-1.48)$ \\
\hline \multicolumn{6}{|l|}{ Pre-existing comorbidities: } \\
\hline Anxiety & $111(7.3 \%)$ & $1.00(0.78-1.27)$ & $1.00(0.78-1.30)$ & $0.99(0.74-1.33)$ & $1.09(0.79-1.50)$ \\
\hline Depression & $271(17.7 \%)$ & $1.00(0.85-1.18)$ & $0.97(0.81-1.16)$ & $1.11(0.91-1.35)$ & $1.11(0.91-1.36)$ \\
\hline Hot flashes & $14(0.9 \%)$ & $0.80(0.40-1.60)$ & $0.93(0.46-1.90)$ & $0.88(0.39-1.96)$ & $0.86(0.38-1.95)$ \\
\hline Musculoskeletal pain & $368(24.0 \%)$ & $1.10(0.96-1.27)$ & $1.25(1.06-1.48)$ & $1.06(0.89-1.27)$ & $0.95(0.77-1.17)$ \\
\hline Osteoporosis & $86(5.6 \%)$ & $0.81(0.61-1.07)$ & $0.77(0.57-1.04)$ & $0.91(0.65-1.28)$ & $0.84(0.59-1.21)$ \\
\hline Vaginal atrophy & $43(2.8 \%)$ & $1.08(0.74-1.57)$ & $1.27(0.87-1.87)$ & $1.05(0.65-1.67)$ & $1.06(0.66-1.72)$ \\
\hline \multicolumn{6}{|l|}{ Newly-treated comorbidities: } \\
\hline Anxiety & $78(5.1 \%)$ & $1.55(1.20-1.99)$ & $1.45(1.11-1.90)$ & $1.46(1.08-1.97)$ & $1.09(0.79-1.50)$ \\
\hline Depression & $271(17.7 \%)$ & $1.19(1.02-1.38)$ & $1.10(0.93-1.30)$ & $1.09(0.90-1.31)$ & $1.11(0.91-1.37)$ \\
\hline Hot flashes & $28(1.8 \%)$ & $1.56(1.03-2.36)$ & $1.16(0.76-1.79)$ & $2.33(1.51-3.60)$ & $2.07(1.32-3.27)$ \\
\hline Musculoskeletal pain & $328(21.4 \%)$ & $1.14(0.99-1.32)$ & $1.15(0.98-1.35)$ & $1.03(0.86-1.23)$ & $0.90(0.73-1.09)$ \\
\hline Osteoporosis & $175(11.4 \%)$ & $0.89(0.74-1.08)$ & $0.93(0.76-1.14)$ & $0.94(0.74-1.18)$ & $0.88(0.69-1.12)$ \\
\hline Vaginal atrophy & $60(3.9 \%)$ & $1.56(1.18-2.06)$ & $1.31(0.98-1.75)$ & $1.56(1.13-2.16)$ & $1.33(0.95-1.88)$ \\
\hline \multicolumn{6}{|l|}{ Location: } \\
\hline Major city & $690(45.1 \%)$ & 1.00 & 1.00 & 1.00 & 1.00 \\
\hline Regional & $544(35.5 \%)$ & $1.05(0.92-1.21)$ & $1.08(0.94-1.24)$ & $1.12(0.95-1.32)$ & $1.10(0.93-1.31)$ \\
\hline Remote & $297(19.4 \%)$ & $0.96(0.81-1.13)$ & $0.94(0.79-1.12)$ & $0.97(0.79-1.19)$ & $0.93(0.75-1.15)$ \\
\hline
\end{tabular}


Table 2 Results of unadjusted and adjusted Cox proportional hazards models for discontinuation of initial or any endocrine therapy, by specified clinical and demographic characteristics (Continued)

\begin{tabular}{|c|c|c|c|c|c|}
\hline \multicolumn{6}{|l|}{ Household income: } \\
\hline$\geq \$ 70,000$ & $272(17.8 \%)$ & 1.00 & 1.00 & 1.00 & 1.00 \\
\hline$\$ 30,000-\$ 69,999$ & 369 (24.1\%) & $0.95(0.79-1.14)$ & $0.94(0.77-1.14)$ & $1.04(0.82-1.31)$ & $1.02(0.79-1.30)$ \\
\hline$<\$ 30,000$ & 477 (31.2\%) & $0.93(0.78-1.11)$ & $0.95(0.76-1.17)$ & $1.13(0.91-1.41)$ & $1.09(0.83-1.42)$ \\
\hline Refused & $413(27.0 \%)$ & $0.80(0.67-0.96)$ & $0.82(0.67-1.01)$ & $0.96(0.77-1.21)$ & $0.90(0.69-1.17)$ \\
\hline \multicolumn{6}{|l|}{ Education: } \\
\hline Undergraduate degree & $330(21.5 \%)$ & 1.00 & 1.00 & 1.00 & 1.00 \\
\hline Certificate or diploma & 395 (25.8\%) & $0.92(0.77-1.09)$ & $0.86(0.72-1.03)$ & $1.01(0.82-1.25)$ & $0.94(0.75-1.17)$ \\
\hline High school or less & 777 (50.7\%) & $0.87(0.75-1.02)$ & $0.88(0.74-1.04)$ & $0.95(0.79-1.15)$ & $0.89(0.72-1.10)$ \\
\hline Missing & $30(2.0 \%)$ & $0.84(0.53-1.34)$ & $0.85(0.52-1.38)$ & $1.03(0.59-1.82)$ & $0.90(0.50-1.63)$ \\
\hline \multicolumn{6}{|l|}{ Marital status: } \\
\hline Partner or spouse & $1084(70.8 \%)$ & 1.00 & 1.00 & 1.00 & 1.00 \\
\hline Single & 79 (5.2\%) & $1.08(0.83-1.41)$ & $1.06(0.80-1.40)$ & $1.12(0.81-1.55)$ & $1.04(0.74-1.46)$ \\
\hline Separated or widowed & 369 (24.1\%) & $0.93(0.80-1.07)$ & $0.95(0.81-1.11)$ & $1.00(0.84-1.19)$ & $0.87(0.72-1.06)$ \\
\hline \multicolumn{6}{|l|}{ Birth country: } \\
\hline Australia & $1143(74.7 \%)$ & 1.00 & 1.00 & 1.00 & 1.00 \\
\hline$N Z, \cup K^{b}$ & $188(12.3 \%)$ & $1.14(0.95-1.36)$ & $1.19(0.99-1.43)$ & $1.42(1.14-1.76)$ & $1.56(1.16-2.10)$ \\
\hline Other & $200(13.1 \%)$ & $0.94(0.78-1.13)$ & $0.90(0.75-1.09)$ & $0.93(0.74-1.17)$ & $1.04(0.83-1.32)$ \\
\hline
\end{tabular}

(Bolded figures indicate $P<0.05$ ).

aprior to commencing endocrine therapy.

${ }^{\mathrm{b}} \mathrm{New}$ Zealand, United Kingdom.

\section{Characteristics associated with discontinuation of any endocrine therapy}

Women commencing therapy with anastrozole were less likely to discontinue any endocrine therapy than those initiated on tamoxifen (unadjusted $\mathrm{HR}=0.6,95 \%$ $\mathrm{CI}=0.5-0.8)$; however this relationship was not significant in the adjusted model (Table 2). None of the pre-existing comorbidities examined predicted duration of endocrine therapy in the unadjusted or adjusted models. Newlytreated anxiety, hot flashes and vaginal atrophy were associated with discontinuation of any therapy in the unadjusted models but only hot flashes remained significant after adjusting for other variables $(\mathrm{HR}=2.1$, 95\% CI $=1.3-3.3$ ).

Clinical characteristics including age, tumour size and stage were not associated with discontinuation of therapy in the adjusted models. However, women not undergoing chemotherapy or mastectomy prior to endocrine therapy were significantly more likely to discontinue therapy by five years compared with women who did receive these treatments (adjusted model, chemotherapy HR $=1.4,95 \%$ $\mathrm{CI}=1.1-1.8$; mastectomy $\mathrm{HR}=1.5,95 \% \mathrm{CI}=1.2-1.8$ ). Women born in the UK or NZ were significantly more likely to discontinue endocrine therapy than Australianborn women $(\mathrm{HR}=1.6,95 \% \mathrm{CI}=1.2-2.1)$. No other demographic characteristics were related to duration of therapy in the unadjusted or adjusted models.

\section{Discussion}

Only $19 \%$ of women receiving endocrine therapy for early breast cancer in clinical practice continued to use their initial therapy for five years. When allowing for switching between therapies, the proportion of women using any endocrine therapy for five years, as consistently recommended by clinical trial evidence (ATAC Trialists' Group 2005; Bliss et al. 2012; Coates et al. 2007; Davies and (ATLAS) (2013); Forbes et al. 2008; Gray and aTTom Collaborative Group 2013), was $42 \%$. These suboptimal persistence rates are similar to discontinuation rates of $31-73 \%$ by five years reported elsewhere (Murphy et al. 2012). The extent of early discontinuation of all endocrine therapy observed here suggests that more than half of treated women do not obtain the benefits of endocrine therapy demonstrated in clinical trials (Hsieh et al. 2014; McCowan et al. 2008; Swedish Breast Cancer Cooperative Group 1996; Yood et al. 2008). Given that tamoxifen duration is now recommended to be 10 years based on ATLAS and aTTom data, this suboptimal efficacy is likely to be magnified in the future (Davies and (ATLAS) (2013); Gray and aTTom Collaborative Group 2013).

We observed different predictors for discontinuation of initial therapy compared with any endocrine therapy. Women were more likely to discontinue their initial therapy if they commenced with tamoxifen, had pre- 
existing arthritis, or were newly-treated for anxiety. The finding that women discontinued initial therapy with tamoxifen earlier than women initiated on anastrozole or letrozole is unsurprising given that trial evidence and clinical guidelines support a switch from tamoxifen to an aromatase inhibitor after 2-3 years for post-menopausal women (Baum et al. 2003; National Breast Cancer Centre (NBCC) and National Health and Medical Research Council (NHMRC) 2001; Winer et al. 2005). Given that tamoxifen is the only endocrine therapy recommended for pre- or peri-menopausal, it is more likely that women would switch from tamoxifen to AIs as therapy progresses than the converse (Cheung 2007; NBCC and NHMRC 2001). Switching from tamoxifen to an AI, rather than the converse, is also more likely because our study covers the period before release of the BIG 1-98 results, which supports use of AIs before a switch to tamoxifen in low and intermediate risk women (Viale et al. 2011). It is encouraging to note that initial therapy type did not influence the total duration of endocrine therapy for women in this study, nor did the other predictors of initial therapy discontinuation: pre-existing musculoskeletal pain and newly-treated anxiety.

Our results showed that the women most likely to discontinue any endocrine therapy before five years were those who did not undergo chemotherapy or mastectomy. This finding remained after adjusting for treatment by a medical oncologist. Previous studies have reported that women not undergoing chemotherapy or mastectomy are more likely to discontinue therapy early. A large observational study of 8769 women followed for 4.5 years found that women undergoing chemotherapy before commencing endocrine therapy were significantly less likely to discontinue than other women, and those who had undergone mastectomy were less likely to discontinue than those who had a lumpectomy (Hershman et al. 2010). A shorter-term study (1 year follow-up) of $>13,000$ women also reported that women with pre-endocrine therapy mastectomy had nearly half the probability of nonadherence compared with women without mastectomy (Sedjo and Devine 2011). It may be that women who undergo more 'aggressive' treatments perceive their condition as more serious and their need for endocrine therapy greater, than other women.

Women in this study first treated for hot flashes after commencing endocrine therapy were at higher risk of early discontinuation than other women. Hot flashes were the side-effect women most commonly cited for discontinuing tamoxifen in Swiss $(N=400)$ and UK studies $(N=110)$ (Charlson et al. 1987; Neugut et al. 2011). Anecdotally, women describe hot flashes as causing sleep disturbance, difficulty concentrating and decreased quality of life. It is interesting to note that only newly-treated, and not pre-existing, hot flashes were associated with early discontinuation. None of the other pre-existing or newlytreated comorbidites we examined were associated with early discontinuation of any endocrine therapy. We may have underestimated treatment for hot flashes in this group because our data did not include non-PBS supply of medicines which might be used for flushing (such as gabapentin and venlafaxine, which are restricted to use for epilepsy and major depression, respectively) (Australian Government Department of Health 2013a).

It is not clear why women born in NZ or the UK would discontinue endocrine therapy earlier than Australianborn women. All of the women in the study were residents of NSW at recruitment to the 45 and Up Study (2006-2009) and reported a median duration of residence in Australia of 37 years (range 26-47). NZ and the UK are culturally similar to Australia, have comparable public pharmaceutical insurance (Kemp et al. 2010), and NZ and UK immigrants to Australia are the most frequent of any countries (Australian Bureau of Statistics 2013). Therefore we consider it unlikely that social marginalisation or unfamiliarity with the health system underpins this higher discontinuation. Further research with this group of women is needed to understand the increased risk of early discontinuation observed here or indeed see if this represents just a spurious finding.

\section{Strengths and weaknesses}

To our knowledge, this is the first observational study with follow-up $>2$ years to examine the impact of initial therapy and specific comorbidities on discontinuation of initial endocrine therapy and any endocrine therapy. Many studies with long follow-up have only examined tamoxifen discontinuation (Barron et al. 2007; Huiart et al. 2011; McCowan et al. 2008; Partridge et al. 2003), and have examined number of comorbidities rather than specific conditions (Kimmick et al. 2009; McCowan et al. 2008; Nekhlyudov et al. 2011; Neugut et al. 2011; van Herk-Sukel et al. 2010; Weaver et al. 2013). Our study is also the first observational study investigating duration of endocrine therapy in Australian clinical practice. Australia's PBS provides subsidised prescription medicines for all Australian residents at relatively low cost (up to $\mathrm{AUS}^{\mathrm{a}} \$ 5.60$ and $\$ 34.20$ per item for social security recipients and other beneficiaries, respectively, as of study end in 2011 (Australian Government Department of Health 2013b; Organisation for Economic Co-operation and Development 2014); therefore cost may be less of a barrier to use in Australia than in some other countries (Kemp et al. 2011).

We used health records for a heterogeneous community sample for whom all publically-subsidised endocrine therapies have been captured. We were able to follow women for up to five years after commencing their initial therapy, with a minimum follow-up time of 2.9 years. 
The findings reported here are comparable to those in previous observational studies of discontinuation as the same definition of discontinuation has been used (180 days), and follow-up was similarly censored for recurrence and death (Barron et al. 2007; Hershman et al. 2010; Nekhlyudov et al. 2011; van Herk-Sukel et al. 2010). Women experiencing troubling side-effects may take a 'drug holiday' from endocrine therapy for up to 3 months (Jordan et al. 2011; Sehdev et al. 2009), and so our use of 180 days to define discontinuation would avoid misclassification of these women.

There are limitations to this study. Our sample was drawn from the 45 and Up Study, limiting the sample to individual's $\geq 45$ years and consenting to linkage of their health records. The health service history of such individuals may differ from younger people, or those who do not agree to participate in cohort studies. Although we could not directly ascertain whether participants had hormone-dependent tumours, endocrine therapies in Australia are only publically-subsidised for hormonedependent tumours (Australian Government Department of Health 2013a). We could not directly assess cancer recurrence and had to 'triangulate' using medicines and services used to treat recurrence. This method of ascertaining breast cancer recurrence has been successfully demonstrated using administrative health service data in previous studies (Earle et al. 2002; Lamont et al. 2006; Stokes et al. 2008). The validity of recurrence using this method has also been compared with chart review with a reported sensitivity and specificity of $92 \%$ and $94 \%$ respectively (Earle et al. 2002).

We were limited to analysing dispensing of endocrine therapy rather than actual consumption. It is not possible to determine whether prescriptions were filled but not taken by women in this study, and similarly women who were prescribed but never dispensed their initial endocrine therapy were not captured. Despite this limitation, prescription refills are used as a measure of adherence and persistence in many endocrine therapy duration studies (Hershman et al. 2010; Huiart et al. 2011; Murphy et al. 2012; van Herk-Sukel et al. 2010) and are consisted an objective and accurate proxy for actual intake (NBCC and NHMRC 2001).

\section{Conclusion}

Less than half of women in this study (42\%) completed five years of endocrine therapy for breast cancer. This suboptimal use means that the full benefit of endocrine therapies in reducing recurrence and cancer-related mortality consistently demonstrated in clinical trials may not be realised in practice. Choice of initial endocrine therapy, pre-existing musculoskeletal pain and newlytreated anxiety were related to shorter duration of initial therapy but not early discontinuation of any therapy.
Women at greatest risk of stopping any endocrine therapy before the recommended five years were those receiving less aggressive initial treatment (i.e. no chemotherapy or mastectomy), those with newly-treated flashes, and those born in UK or NZ. Strategies are needed to support medicine use and improve outcomes for these women.

\section{Ethics statement}

This study was conducted in accordance with Australian law. The consent procedure for entry to the 45 and Up Study was approved by the University of NSW Human Research Ethics Committee and the Australian Government Department of Health and Ageing. The current study also received approval from The University of Western Australia Human Research Ethics Committee (approval RA/4/1/4589), and the NSW Population and Health Services Research Ethics Committee (approval HREC/11/CIPHS/35).

\section{Endnote}

${ }^{a}$ In 2011, the purchasing power of $1 \$$ US was 1.51 AUS dollars.

\section{Competing interests}

The authors declare that they have no conflicts of interests.

\section{Authors' contributions}

AK and ER conceived of the study and interpreted data. AK performed the statistical analyses and drafted the manuscript. MB and EM aided with data interpretation and critically reviewed the statistical content of the manuscript. DP, CS, FB, and MB assisted with acquisition of data and critically reviewed the manuscript. All authors read and approved the final manuscript.

\section{Acknowledgments}

This research was completed using data collected through the 45 and Up Study (www.saxinstitute.org.au). The 45 and Up Study is managed by the Sax Institute in collaboration with major partner Cancer Council NSW; and partners: the National Heart Foundation of Australia (NSW Division); NSW Ministry of Health; beyondblue; Ageing, Disability and Home Care, Department of Family and Community Services; the Australian Red Cross Blood Service; and UnitingCare Ageing. We thank the many thousands of people participating in the 45 and Up Study. This study was jointly-funded by Cancer Australia and the National Breast Cancer Foundation.

\section{Author details}

${ }^{1}$ Centre for Health Services Research, School of Population Health, The University of Western Australia, 35 Stirling Hwy, Crawley, WA 6009, Australia. ${ }^{2}$ School of Surgery, The University of Western Australia, 35 Stirling Hwy, Crawley, WA 6009, Australia. ${ }^{3}$ Patricia Richie Centre for Cancer Care and Research, The Mater Hospital, University of Sydney, Rocklands Road, North Sydney, NSW 2060, Australia. ${ }^{4}$ Institute of Health and Rehabilitation Research, University of Notre Dame, PO Box 1225, Fremantle, WA 6959, Australia. ${ }^{5}$ Quality Use of Medicines and Pharmacy Research Centre, School of Pharmacy and Medical Sciences, University of South Australia, GPO Box 2471, Adelaide, SA 5001, Australia.

Received: 22 May 2014 Accepted: 22 May 2014

Published: 4 June 2014

\section{References}

45 and Up Study Collaborators (2008) Cohort profile: the 45 and Up Study. Int J Epidemiol 37(5):941-947 
ATAC Trialists' Group (2005) Results of the ATAC (Arimidex, Tamoxifen, Alone or in Combination) trial after completion of 5 years' adjuvant treatment for breast cancer. Lancet 365:60-62

Australian Bureau of Statistics (2013) 3412.0 - Migration, Australia, 2011-12 and 2013-13, http://www.abs.gov.au/ausstats/abs@.nsf/Lookup/3412.0 Chapter12011-12\%20and\%202012-13. Accessed April 82014

Australian Government Department of Health (2013a) Schedule of pharmaceutical benefits, 1 October 2013. Department of Health, http://www.pbs.gov.au/pbs/home. Accessed October 312013

Australian Government Department of Health (2013b) Fees, patient contributions and safety net thresholds, history of PBS copayments and safety net thresholds. Department of Health, http://www.pbs.gov.au/info/healthpro/ explanatory-notes/front/fee. Accessed October 312013

Australian Population and Migration Research Centre (2013) Accessibility and Remoteness Index of Australia (ARIA). The University of Adelaide, http://adelaide.edu.au/apmrc/research/projects/category/about_aria.html. Accessed October 312013

Barron TI, Connolly RM, Bennett K, Feely J, Kennedy MJ (2007) Early discontinuation of tamoxifen: a lesson for oncologists. Cancer 109(5):832-839

Baum M, Buzdar A, Cuzick J, Forbes J, Houghton J, Howell A, Sahmoud T, ATAC (Arimidex TAoiCTG) (2003) Anastrozole alone or in combination with tamoxifen versus tamoxifen alone for adjuvant treatment of postmenopausal women with early-stage breast cancer: results of the ATAC (Arimidex, Tamoxifen Alone or in Combination) trial efficacy and safety update analyses. Cancer 98:1802-1810

Bell JB, Fradkin P, Schwarz M, Davis SR (2013) Understanding discontinuation of oral adjuvant endocrine therapy by women with hormone receptor-positive invasive breast cancer nearly 4 years from diagnosis. Menopause 20(1):1-5

Bliss JM, Kilburn LS, Coleman RE, Forbes JF, Coates AS, Jones SE, Jassem J, Delozier T, Andersen J, Paridaens R, van de Velde CJH, Lonning PE, Morden J, Reise J, Cisar L, Menschik T, Coombes RC (2012) Disease-related outcomes with long-term follow-up: an updated analysis of the Intergroup Exemestane Study. J Clin Oncol 30(7):709-717, doi: 10.1200/jco.2010.33.7899

Centre for Health Record Linkage (CHeReL) (2009) Information for researchers. CHeReL., http://www.cherel.org.au/. Accessed October 312013

Charlson ME, Pompei P, Ales KL, MacKenzie CR (1987) A new method of classifying prognostic comorbidity in longitudinal studies: development and validation. J Chronic Dis 40(5):373-383

Cheung KL (2007) Endocrine therapy for breast cancer: an overview. Breast 16:327-343

Chim K, Xie SX, Stricker CT, Li QS, Gross R, Farrar JT, DeMichele A, Mao JJ (2013) Joint pain severity predicts premature discontinuation of aromatase inhibitors in breast cancer survivors. BMC Cancer 13:401

Coates A, Keshaviah A, Thürlimann B, Mouridsen H, Mauriac L, Forbes JF, Paridaens R, Castiglione-Gertsch M, Gelber RD, Colleoni M, Láng I, Del Mastro L, Smith I, Chirgwin J, Nogaret J, Pienkowski T, Wardley A, Jakobsen EH, Price KN, Goldhirsch A (2007) Five years of letrozole compared with tamoxifen as initial adjuvant therapy for postmenopausal women with endocrine-responsive early breast cancer: update of study BIG 1-98. J Clin Oncol 25:486-492

Davies C, Adjuvant Tamoxifen: Longer Against Shorter (ATLAS) Collaborative Group (2013) Long-term effects of continuing adjuvant tamoxifen to 10 years versus stopping at 5 years after diagnosis of oestrogen receptor-positive breast cancer: ATLAS, a randomised trial. Lancet 381(9869):805-816

Demissie S, Silliman RA, Lash TL (2001) Adjuvant tamoxifen: predictors of use, side effects, and discontinuation in older women. J Clin Oncol 19(2):322-328

Earle CC, Nattinger AB, Potosky AL, Lang K, Mallick R, Berger M, Warren JL (2002) Identifying cancer relapse using SEER-Medicare data. Med Care 40(8):IV-75-IV-81

Fallowfield L, Cella D, Cuzick J, Francis S, Locker G, Howell A (2004) Quality of life of postmenopausal women in the Arimidex, Tamoxifen, Alone or in Combination (ATAC) adjuvant breast cancer trial. J Clin Oncol 22(21):4261-4271, doi: 10.1200/jco.2004.08.029

Forbes JF, Cuzick J, Buzdar A, Howell A, Tobias JS, Baum M (2008) Effect of anastrozole and tamoxifen as adjuvant treatment for early-stage breast cancer: 100-month analysis of the ATAC trial. Lancet Oncol 9(1):45-53

Gray RG, aTTom Collaborative Group (2013) aTTom: long-term effects of continuing adjuvant tamoxifen to 10 years versus stopping at 5 years in 6,953 women with early breast cancer. J Clin Oncol 31 (suppl, abstract 5)
Grunfeld EA, Hunter MS, Sikka P, Mittal S (2005) Adherence beliefs among breast cancer patients taking tamoxifen. Patient Educ Couns 59(1):97-102, www.sciencedirect.com/science/article/pii/S0738399104003350

Güth U, Myrick ME, Schötzau A, Kilic N, Schmid SM (2011) Drug switch because of treatment-related adverse side effects in endocrine adjuvant breast cancer therapy: how often and how often does it work? Breast Cancer Res Treat 129(3):799-807, http://dx.doi.org/10.1007/s10549-011-1668-y

Hershman DL, Kushi LH, Shao T, Buono D, Kershenbaum A, Tsai W-Y, Fehrenbacher L, Gomez SL, Miles S, Neugut Al (2010) Early discontinuation and nonadherence to adjuvant hormonal therapy in a cohort of 8,769 early-stage breast cancer patients. J Clin Oncol, doi:10.1200/jco.2009.25.9655

Hsieh K-P, Chen L-C, Cheung K-L, Chang C-S, Yang Y-H (2014) Interruption and non-adherence to long-term adjuvant hormone therapy is associated with adverse survival outcome of breast cancer women - an Asian populationbased study. PLoS One 9(2):e87027, doi: 10.1371/journal.pone.0087027

Huiart L, Dell'Aniello S, Suissa S (2011) Use of tamoxifen and aromatase inhibitors in a large population-based cohort of women with breast cancer. Br J Cancer 104(10):1558-1563, doi: 10.1038/bjc.2011.140

Jordan VC, Obiorah I, Fan P, Kim HR, Ariazi E, Cunliffe H, Brauch H (2011) Evolution of long-term adjuvant anti-hormone therapy: consequences and opportunities. The St. Gallen prize lecture. Breast 20(Suppl 3):S1-S11

Kemp A, Roughead E, Preen DB, Glover J, Semmens J (2010) Determinants of self-reported medicine underuse due to cost: a comparison of seven countries. J Health Serv Res Pol 15(2):106-114

Kemp A, Preen D, Glover J, Semmens J, Roughead E (2011) How much do we spend on prescription medicines? Out-of-pocket costs for patients in Australia and other OECD countries. Aust Health Rev 35:341-349

Kimmick G, Anderson R, Camacho F, Bhosle M, Hwang W, Balkrishnan R (2009) Adjuvant hormonal therapy use among insured, low-income women with breast cancer. J Clin Oncol 27(21):3445-3451, doi: 10.1200/jco.2008.19.2419

Lamont EB, Herndon JE, Weeks JC, Henderson IC, Earle CC, Schilsky RL (2006) Measuring disease-free survival and cancer relapse using Medicare claims from CALGB Breast Cancer Trial Participants (companion to 9344). J Natl Cancer Inst 98(18):1335-1338

McCowan C, Shearer J, Donnan PT, Dewar JA, Crilly M, Thompson AM, Fahey TP (2008) Cohort study examining tamoxifen adherence and its relationship to mortality in women with breast cancer. Br J Cancer 99:1763-1768

Murphy C, Bartholomew L, Carpentier M, Bluethmann S, Vernon S (2012) Adherence to adjuvant hormonal therapy among breast cancer survivors in clinical practice: a systematic review. Breast Cancer Res Treat 134(2):459-478, doi: 10.1007/s10549-012-2114-5

NBCC, NHMRC (2001) Clinical practice guidelines for the management of early breast cancer: second edition. NBCC, NHMRC, http://www.nhmrc.gov.au/ guidelines/publications/cp74. Accessed October 312013

Nekhlyudov L, Li L, Ross-Degnan D, Wagner AK (2011) Five-year patterns of adjuvant hormonal therapy use, persistence, and adherence among insured women with early-stage breast cancer. Breast Cancer Res Treat 130(2):681-689

Neugut Al, Subar M, Wilde ET, Stratton S, Brouse CH, Hillyer GC, Grann VR, Hershman DL (2011) Association between prescription co-payment amount and compliance with adjuvant hormonal therapy in women with early-stage breast cancer. J Clin Oncol 29(18):2534-2542, doi: 10.1200/jco.2010.33.3179

Organisation for Economic Co-operation and Development (2014) 2011 PPP benchmark results. OECD, http://stats.oecd.org/. Accessed April 152014

Owusu C, Buist D, Field T, Lash T, Thwin S, Geiger A (2008) Predictors of tamoxifen discontinuation among older women with estrogen receptor-positive breast cancer. J Clin Oncol 26(4):549-555

Partridge AH, Wang PS, Winer EP, Avorn J (2003) Nonadherence to adjuvant tamoxifen therapy in women with primary breast cancer. J Clin Oncol 21(4):602-606

Partridge A, LaFountain A, Mayer E, Taylor B, Winer E, Asnis-Alibozek A (2008) Adherence to initial adjuvant anastrozole therapy among women with early-stage breast cancer. J Clin Oncol 26(4):556-562

Sedjo R, Devine S (2011) Predictors of non-adherence to aromatase inhibitors among commercially insured women with breast cancer. Breast Cancer Res Treat 125(1):191-200, doi: 10.1007/s10549-010-0952-6

Sehdev S, Martin G, Sideris L, Lam W, Brisson S (2009) Safety of adjuvant endocrine therapies in hormone receptor-positive early breast cancer. Curr Oncol 16(Suppl 2):S14-S23

Stokes M, Thompson D, Montoya EL, Weinstein MC, Winer EP, Earle CC (2008) Ten-year survival and cost following breast cancer recurrence: estimates from SEER-Medicare data. Value Health 11(2):213-220 
Swedish Breast Cancer Cooperative Group (1996) Randomized trial of two versus five years of adjuvant tamoxifen for postmenopausal early stage breast cancer. J Natl Cancer Inst 88(21):1543-1549, doi: 10.1093/jnci/88.21.1543

van Herk-Sukel MP, van de Poll-Franse LV, Voogd AC, Nieuwenhuijzen GAP, Coebergh JWW, Herings RMC (2010) Half of breast cancer patients discontinue tamoxifen and any endocrine treatment before the end of the recommended treatment period of 5 years: a population-based analysis. Breast Cancer Res Treat 122(3):843-851

Viale G, Regan MM, Dell'Orto P, Mastropasqua MG, Maiorano E, Rasmussen BB, MacGrogan G, Forbes JF, Paridaens RJ, Colleoni M, Láng I, Thürlimann B, Mouridsen H, Mauriac L, Gelber RD, Price KN, Goldhirsch A, Gusterson BA, Coates AS, Collaborative ftB-, Groups IBCS (2011) Which patients benefit most from adjuvant aromatase inhibitors? Results using a composite measure of prognostic risk in the BIG 1-98 randomized trial. Ann Oncol, doi:10.1093/annonc/mdq738

Weaver K, Camacho F, Hwang W, Anderson R, Kimmick G (2013) Adherence to adjuvant hormonal therapy and its relationship to breast cancer recurrence and survival among low-income women. Am J Clin Oncol 36:181-187

Winer EP, Hudis C, Burstein HJ, Wolff AC, Pritchard Kl, Ingle JN, Chlebowski RT, Gelber R, Edge SB, Gralow J, Cobleigh MA, Mamounas EP, Goldstein LJ, Whelan TJ, Powles TJ, Bryant J, Perkins C, Perotti J, Braun S, Langer AS, Browman GP, Somerfield MR (2005) American Society of Clinical Oncology technology assessment on the use of aromatase inhibitors as adjuvant therapy for postmenopausal women with hormone receptor-positive breast cancer: status report 2004. J Clin Oncol 23(3):619-629, doi: 10.1200/jco.2005.09.121

Yood MU, Owusu C, Buist DSM, Geiger AM, Field TS, Thwin SS, Lash TL, Prout MN, Wei F, Quinn VP, Frost FJ, Silliman RA (2008) Mortality impact of less-than-standard therapy in older breast cancer patients. J Am Coll Surg 206(1):66-75, http://dx.doi.org/10.1016/j.jamcollsurg.2007.07.015

doi:10.1186/2193-1801-3-282

Cite this article as: Kemp et al:: Early discontinuation of endocrine therapy for breast cancer: who is at risk in clinical practice? SpringerPlus 2014 3:282.

\section{Submit your manuscript to a SpringerOpen ${ }^{\circ}$ journal and benefit from:}

- Convenient online submission

- Rigorous peer review

- Immediate publication on acceptance

- Open access: articles freely available online

- High visibility within the field

- Retaining the copyright to your article

Submit your next manuscript at $>$ springeropen.com 